\title{
Extralobar infradiaphragmatic pulmonary sequestration with a digestive communication
}

\author{
R. Carrasco, MD, M. Castañón, MD, B. San Vicente, MD, X. Tarrado, MD, A. Montaner, MD, and L. Morales, MD, \\ Barcelona, Spain
}

$\mathrm{P}$ ulmonary sequestration is a congenital malformation within the spectrum of bronchopulmonary foregut anomalies. This pathologic condition was first described by Rokitansky ${ }^{1}$ and Rektorzik ${ }^{2}$ in 1861 with the term "accessory pulmonary lobe." It was renamed "pulmonary sequestration" by Price ${ }^{3}$ in 1946. This type of malformation of the lung receives blood supply from one or more systemic arteries and may or may not communicate with the bronchial tree. Incidence of pulmonary sequestration ranges between $0.15 \%$ and $1.7 \%{ }^{4}$ Two different forms have been described: intralobar and extralobar. Intralobar sequestration is localized within the normal pulmonary parenchyma whereas extralobar forms are totally separate from the lung and usually have their own pleural covering. Infradiaphragmatic pulmonary sequestration belongs to the extralobar type, and most cases have been reported in the suprarenal area associated with other congenital malformations. ${ }^{5}$

Since 1990, 13 patients with pulmonary sequestration have been operated on in our hospital. In 10 patients, sequestration was

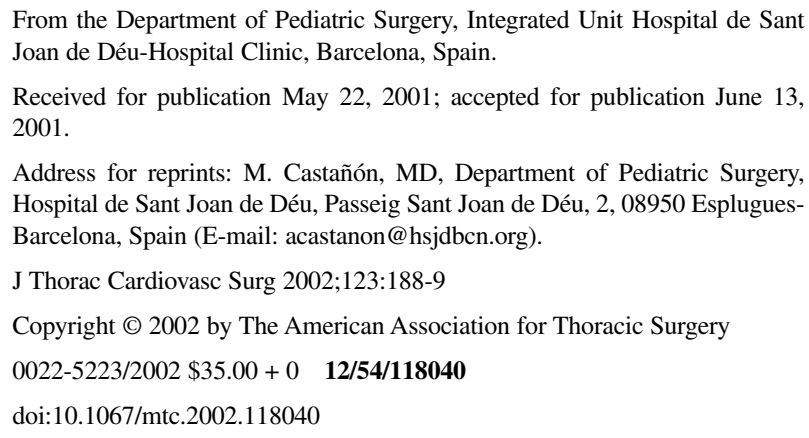

188 The Journal of Thoracic and Cardiovascular Surgery • January 2002 intralobar. The pathologic tissue was localized in the right lower lobe in 7 patients and in the left lower lobe in 3 patients. Sequestration was extralobar in another 3 patients, and 1 of them, the case reported here, was infradiaphragmatic.

\section{Clinical Summary}

A left suprarenal mass, consistent with the radiologic diagnosis of neuroblastoma, was found in a 21-week-old fetus by routine antenatal ultrasonography. The baby was born without complications at 38 weeks weighing $3250 \mathrm{~g}$, and no masses were detected on palpation of the abdomen. The mother's medical history was remarkable only for gestational diabetes. A postnatal ultrasound (Figure 1) revealed a homogeneous suprarenal mass measuring $2 \times 2 \mathrm{~cm}$ compatible with the prenatal diagnosis. An abdominal computed tomographic scan showed a solid tumor at the same location with small hypodense areas inside (Figure 2). Bone marrow punction showed no abnormalities and tumor markers for neuroblastoma were negative.

Surgical treatment was indicated, and a $3-\mathrm{cm}$ solid tumor adherent to the lower esophagus and greater gastric curvature was found at laparotomy 48 hours after birth. The mass had a narrow communication with the stomach and was completely excised with no complications. Postoperative recovery was uneventful.

Histopathologic examination was consistent with the diagnosis of extralobar pulmonary sequestration. The mass was composed of immature lung tissue with a principal bronchus and bronchioles and cystic dilatations. Alveolar structures were scarce.

\section{Discussion}

The present case is a very unusual type of pulmonary sequestration, a congenital malformation within the spectrum of bronchopulmonary foregut anomalies along with bronchogenic cyst and cystic adenomatoid malformation. These malformations 


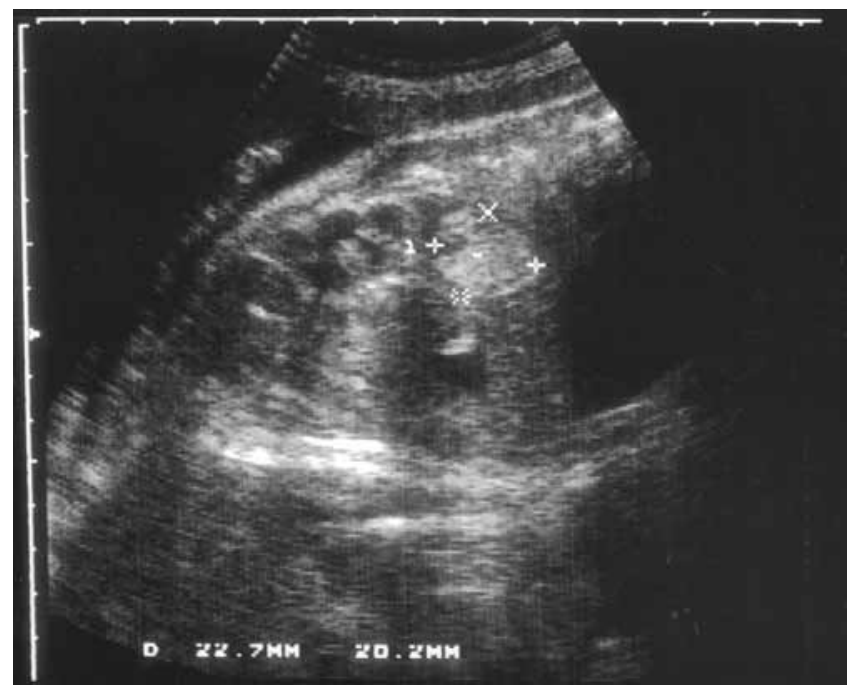

Figure 1. Postnatal ultrasound revealed a homogeneous suprarenal mass (highlighted) measuring $2 \times 2 \mathrm{~cm}$ compatible with the prenatal diagnosis of neuroblastoma.

occur simultaneously and in association with other anomalies such as gastric and esophageal diverticula. The combination of these malformations supports a common origin from the foregut. In 1968, Gerle, Jaretzki, and Ashley 6 introduced the term "bronchopulmonary foregut malformation" in reference to pulmonary sequestrations with a communication with the esophagus or stomach. This communication with the gastrointestinal tract may be an obliterated fibrous cord or a patent tract, ${ }^{7}$ as in our case. It has recently been proposed that the name "bronchopulmonary foregut malformation" be applied to all anomalies of the tracheobronchial tree originating during the development from the foregut. ${ }^{8}$

Extralobar intra-abdominal pulmonary sequestration is extremely uncommon. In most cases the sequestration has been close to the diaphragm, in the left suprarenal area, and it has been associated with other congenital malformations in approximately $50 \%$ of cases. Diaphragmatic hernia, pericardial defects, pectus excavatum, and congenital heart disease are the most frequently reported associated anomalies. ${ }^{9,10}$ It is remarkable that in our case intra-abdominal sequestration with gastric communication was an isolated malformation.

Prenatal diagnosis is difficult, most cases being diagnosed during the histopathologic study of a resected mass found during routine ultrasonography. Several ultrasonographic characteristics have been described to help in the differential diagnosis, such as the presence of calcifications in a homogeneous and echogenic mass. Differential diagnosis includes suprarenal neuroblastoma, teratoma, foregut duplication, and cystic adenomatoid malformation. The latter is also a congenital lung anomaly characterized by a mass of cysts that may contain different types of tissue such as cartilage, muscle, and mucous glands. Carcinomas and rhabdomyosarcomas have been reported to originate in cystic adenomatoid malformations. ${ }^{11}$

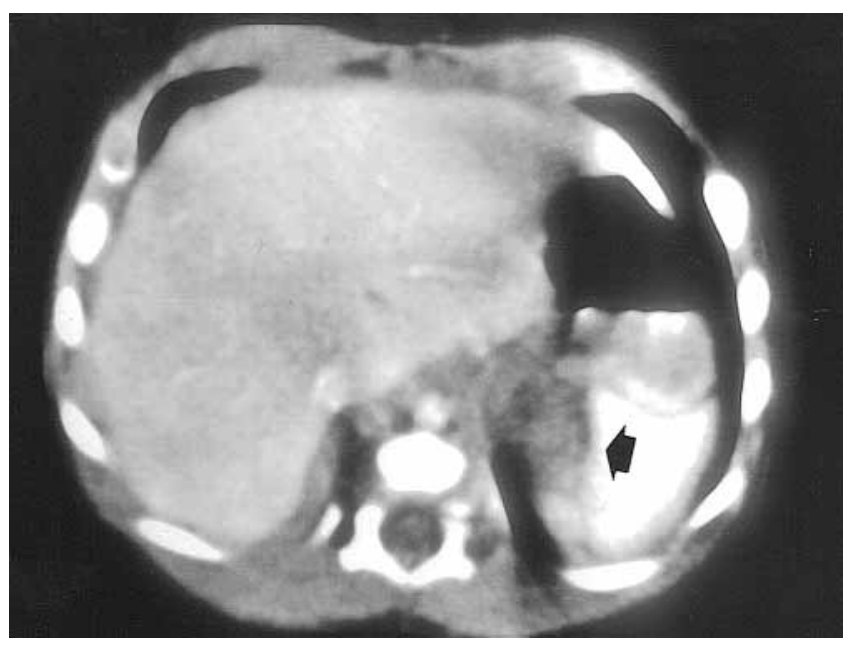

Figure 2. Abdominal computed tomographic scan demonstrating a solid tumor containing small hypodense areas (arrow).

Treatment of intra-abdominal pulmonary sequestration is controversial. Spontaneous regression has been reported in patients with intralobar or extralobar intrathoracic sequestration. ${ }^{12}$ On this basis, some authors have proposed a close follow-up with imaging studies. However, surgical excision should be performed whenever the diagnosis of neuroblastoma or cystic adenomatoid malformation cannot be excluded. ${ }^{9}$

\section{References}

1. Rokitansky C. Lehrbuch der pathologischen Anatomie, ed 3. Vienna: 1861. p. 44.

2. Rektorzik E. Ueber accessorische Lungenlapen. Wochenbl Z Ges Aerzte. 1861;17:4-6.

3. Pryce DM. Lower accessory pulmonary artery with intralobar sequestration of lung: a report of seven cases. J Pathol. 1946;58:457-67.

4. Weinbaum PJ, Bors-Koefoed R, Green K. Antenatal ultrasonographic findings in a case of intra-abdominal pulmonary sequestration. Obstet Gynecol. 1989;73:860-1.

5. Samuel M, Burge DM. Extra-lobar intra-abdominal pulmonary sequestration. Eur J Pediatr Surg. 1996;6:107-9.

6. Gerle RD, Jaretzki A 3rd, Ashley CA. Congenital bronchopulmonary foregut malformation. N Engl J Med. 1968;278:1413-9.

7. Tovar J, Benavent MI. Diaphragmatic hernia associated with double pulmonary sequestration. J Pediatr Surg. 1979;14:604-6.

8. Srikanth MS, Ford EG, Stanley P, Mahour GH. Communicating bronchopulmonary foregut malformations: classification and embryogenesis. J Pediatr Surg. 1992;27:732-6.

9. Black MD, Bass J, Martin DJ, Carpenter BF. Intraabdominal pulmonary sequestration. J Pediatr Surg. 1983;26:1381-3.

10. Eizaguirre I, Tovar J, Conde J. Pulmonary sequestration with esophagobronchial fistula: presentation of 2 cases and a review of the literature. An Esp Pediatr. 1989;31:297-301.

11. Morad NA, al-Malki T, e-Tahir M. Intra-abdominal pulmonary sequestration: diagnostic difficulties. Pathology. 1997;29:218-20.

12. Garcia-Pena P, Lucaya J, Hendry GM, McAndrew PT, Duran C. Spontaneous involution of pulmonary sequestration in children: a report of two cases and review of the literature. Pediatr Radiol. 1998;28:266-70. 